\title{
Impact of liver cirrhosis on the clinical outcomes of patients with COVID-19: a nationwide cohort study of Korea
}

\author{
Dongsub Jeon ${ }^{1,{ }^{*}}$, Minkook Son ${ }^{2,}$, and Jonggi Choi ${ }^{1}$
}

${ }^{1}$ Department of Gastroenterology, Liver Center, Asan Medical Center, University of Ulsan College of Medicine, Seoul; ${ }^{2}$ Department of Biomedical Science and Engineering, Gwangju Institute of Science and Technology, Gwangju, Korea

Received: September 4, 2020 Revised : October 30, 2020 Accepted: November 17, 2020

\section{Correspondence to Jonggi Choi, M.D. \\ Department of Gastroenterology, Asan Medical Center, University of Ulsan College of Medicine, 88 Olympic-ro 43-gil, Songpa-gu, Seoul 05505, Korea \\ Tel: $+82-2-3010-1328$ \\ Fax: $+82-2-485-5782$ \\ E-mail:j.choi@amc.seoul.kr https://orcid.org/0000-0002- $7470-5850$}

*These authors contributed equally to this work.
Background/Aims: The impact of liver cirrhosis (LC) on the clinical outcomes of patients with coronavirus disease 2019 (COVID-19) remains elusive. This study evaluated the association between LC and the development of severe complications from COVID-19.

Methods: We used the National Health Insurance claims data of Korea. We included 234,427 patients older than 19 years who tested for severe acute respiratory syndrome coronavirus 2. Patients with LC who were infected with COVID-19 ( $\mathrm{n}=67$, LC+ COVID+) were matched with those with cirrhosis only ( $n=332$, LC+ COVID-) and those with COVID-19 only ( $\mathrm{n}=333$, LC- COVID+) using a propensity score in a 1:5 ratio. The primary outcome was the development of severe complications.

Results: Of the matched patients, the mean age was 60 years and $59.7 \%$ were male. Severe complications occurred in 18, 54, and 60 patients in the LC+ COVID+, LC+ COVID-, and LC-COVID+ groups, respectively. After adjusting for comorbidities, there was no significant difference in the risk of developing severe complications from COVID-19 between the LC+ COVID+ and LC- COVID+ groups but significant difference exists between the LC+ COVID+ and LC+ COVID-. Older age, hypertension, cancer, chronic obstructive pulmonary disease, and a higher Charlson comorbidity index were associated with a higher risk of severe complications in patients with cirrhosis and COVID-19.

Conclusions: Our study suggests that LC was not independently associated with the development of severe complications, including mortality, in patients with COVID-19. Our results need to be evaluated through a large, prospective study.

Keywords: Liver cirrhosis; COVID-19; Comorbidity; Mortality

\section{INTRODUCTION}

The severe acute respiratory syndrome coronavirus 2 (SARS-CoV-2) is a novel coronavirus that causes the coronavirus disease 2019 (COVID-19) which first appeared in Wuhan City in Hubei Province in central China. It is highly contagious and is rapidly spreading around the world [1]. The clinical severity of COVID-19 varies from asymptomatic to fatal. Some cases are only accompanied by mild respiratory symptoms without fever and recover spontaneously [2]. In contrast, others suffer from systemic symptoms including fever, chest pain, myalgia, shortness of breath and coughing associated with pneumonia, which contribute in part to the development of severe complications such as acute respiratory distress syndrome, and even death [3]. 
Previous studies reported several underlying medical conditions as risk factors associated with severe complications in patients with COVID-19 [4-6]. Varying degrees of liver enzyme elevation were reported in $20 \%$ to $30 \%$ of patients with COVID-19 in one meta-analysis [7] and up to $58 \%$ of patients with COVID-19 in another large case-series [8]. The prevalence of pre-existing liver disease and liver cirrhosis (LC) in patients with COVID-19 range from $2 \%$ to $11 \%$ and $0.4 \%$, respectively $[7,8]$. Given that the homeostatic role of the liver in the systemic immune response is impaired in patients with cirrhosis which causes inherent immune dysfunction [9], their prognosis after infection with COVID-19 might be thought worse than the prognosis in those without cirrhosis. A few studies have reported high mortality in COVID-19 patients with LC [10-13]. However, most studies so far have been a small number of case reports or series, which give limited insight into the impact of LC on the clinical outcomes of patients with COVID-19 [14]. Therefore, our study aimed to determine the impact of cirrhosis on the clinical outcomes of patients infected with COVID-19 (LC+ COVID+) by comparing the prognosis in cirrhotic patients without COVID-19 (LC+ COVID-) and in those without cirrhosis infected with COVID-19 (LC- COVID+) in a large-scale, nationwide cohort of Korea.

\section{METHODS}

\section{Data source and study population}

This study was approved by the Institutional Review Board of the Asan Medical Center (IRB No. 2020-1153). The board approved a waiver of written informed consent for deidentified data. The completely anonymized data obtained from the National Health Insurance claims of the Republic of Korea were analyzed. As of May 15, 2020, the current population-based dataset comprised all cases tested for COVID-19, including suspected and confirmed cases, with the demographic information and history of medical services accessed for the past 3 years.

The approach to the study population is presented in Fig. 1. The study involved 234,427 individuals tested for COVID-19 based on the 1oth revision of the International Statistical Classification of Disease and Relat-

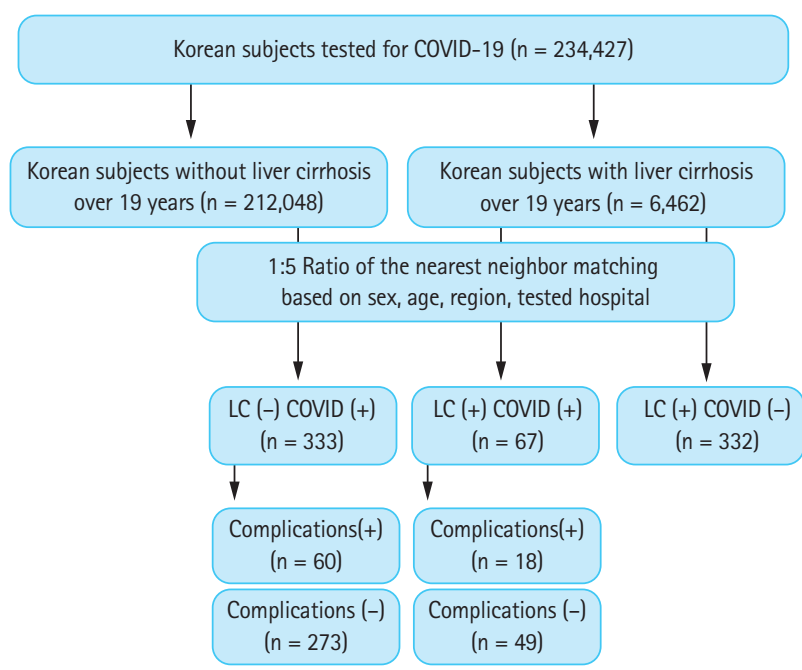

Figure 1. Inclusion flow-chart for the study population. COVID-19, coronavirus disease 2019; LC, liver cirrhosis.

ed Health Problems (ICD-10) codes of B342, B972, Z208, Z290, U18, U181, Zo38, Z115, Uo71, and Uo72. COVID-19 was confirmed in the Republic of Korea using polymerase chain reaction amplification of the viral E gene as a screening test, and amplification of the RNA-dependent RNA polymerase region of the open reading frame $1 \mathrm{~b}$ gene as a confirmatory test [15]. In total, 6,462 patients with LC and 212,048 individuals without LC aged over 19 years were analyzed. The presence of LC was established based on the ICD-10 codes for LC (K702-K704, K717, $\mathrm{K}_{720}$, K721, K729, K740-K746, K761, K766, K767, R18, I850, I859, I864, I868, I982, I983) [16]. Among the patients with cirrhosis, 67 (1.0\%) were confirmed as COVID-19+. Of the individuals without cirrhosis, 7,219 (3.4\%) were confirmed as COVID-19+. To analyze the impact of cirrhosis on COVID-19+ patients (LC+ COVID+), we matched them with patients with LC but without COVID-19 (LC+ COVID-) and those without LC but with COVID-19 (LCCOVID+) at a ratio of 1:5 based on covariates such as sex, age, region, and the hospital in which they were tested. The matching was exact for the sex, region, and tested hospital, but nearest neighbor matching was performed for age, with a caliper of 0.1 in the propensity scores. The numbers of matched patients in the LC+ COVID+, LC+ COVID-, and LC- COVID+ groups were 67, 332, and 333, respectively (Fig. 1). 


\section{Data collection and definitions}

Comorbidities were established based on the ICD-10 diagnosis codes (Supplementary Table 1). The conditions that were considered as comorbidities were decompensated LC, diabetes, hypertension, dyslipidemia, cardiovascular disease including myocardial infarction and stroke, cancer, chronic obstructive pulmonary disease (COPD), asthma, end-stage renal disease with dialysis, and an immunocompromised status including autoimmune diseases and human immunodeficiency virus infection. The definitions of each comorbidity are presented in Supplementary Table 1. The Charlson comorbidity index (CCI) was also used as a variable and was calculated based on the patient's pre-existing diseases including myocardial infarction; congestive heart failure; dementia; diabetes with or without complications; paraplegia or hemiplegia; cancer with or without metastases; acquired immune deficiency syndrome; and peripheral vascular, cerebrovascular, chronic obstructive pulmonary, connective tissue, peptic ulcer, liver, and renal disease [17].

\section{Outcome measurement}

The primary outcome of this study was severe complications that required interventions including oxygen therapy, the use of vasopressors, admission to intensive care unit (ICU), continuous renal replacement therapy, and death $[18,19]$. LC-related complications included variceal bleeding, ascites, hepatorenal syndrome, spontaneous bacterial peritonitis, and hepatic encephalopathy [20]. The definitions of each treatment are presented in Supplementary Table 2 . Additionally, we separately analyzed patients in the LC+ COVID+ and LC- COVID+ groups according to whether they developed complications. Of these 67 cirrhotic patients with COVID-19, 18 (26.9\%) patients developed severe complications, whereas the other 49 (73.1\%) did not experience severe complication despite COVID-19 infection.

\section{Statistical analysis}

The baseline characteristics of the three groups were presented as the mean with the standard deviation for continuous variables, and as a percentage (\%) for categorical variables. Comparisons between the groups were performed using analysis of variance or Student's $t$ test for continuous variables, and the chi-square or Fisher's exact tests for categorical variables. After 1:5 ratio matching, the odds ratio and 95\% confidence interval were calculated with conditional logistic regression analysis. We utilized three models for the multivariable-adjusted analysis and, because of the small study population, we selected some variables for adjustment. Model 1 was adjusted for hypertension, dyslipidemia, and CCI because CCI does not include these comorbidities. Model 2 was adjusted for decompensated LC, hypertension, cardiovascular disease, cancer, COPD, end-stage renal disease with dialysis, and CCI, with $p<0.10$ considered as significant in the univariate analysis that compared LC+ COVID+ and LC+ COVID-. Model 3 was adjusted for decompensated LC, diabetes, cancer, immunocompromised status, and CCI, with $p<0.10$ considered as significant in the univariate analysis that compared LC+ COVID+ and LC-COVID+. The statistical software SAS version 9.4 (SAS Inc., Cary, NC, USA) was used to perform all statistical analyses. A $p<0.05$ was considered statistically significant.

\section{RESULTS}

\section{Baseline characteristics}

The baseline characteristics of the three groups before matching are shown in Supplementary Table 3. After matching, a total of 732 patients were analyzed and the baseline characteristics of the study population are presented in Table 1. Of the entire study population, the mean age was 60.0 years and $59.7 \%$ were male. There were no significant differences in the demographics such as age, sex, and region of diagnosis between the three groups (Table 1). In terms of comorbidities, the prevalence of diabetes, cancer, and immunocompromised statuses were significantly higher in the LC+ COVID+ and LC+ COVID- groups, when compared with the LC-COVID+ group. The LC+ COVID- group had the highest CCI, followed by the LC+ COVID+ and LC-COVID+ groups. Of the 399 patients with cirrhosis, 19 and $154(28.4 \%$ and $46.4 \%)$ of the 67 and 332 patients in the LC+ COVID+ and LC+ COVID- groups, respectively, showed decompensated cirrhosis.

\section{Severe complications and LC-related complications}

Of the 732 patients included in the study, 132 (18.0\%) ex- 
Table 1. Baseline characteristics of patients with liver cirrhosis grouped according to COVID-19 infection status (n= 732)

\begin{tabular}{|c|c|c|c|c|}
\hline Characteristic & $\begin{array}{c}\text { LC+ COVID+ } \\
\quad(\mathrm{n}=67)\end{array}$ & $\begin{array}{l}\text { LC+ COVID- } \\
\quad(\mathrm{n}=332)\end{array}$ & $\begin{array}{c}\text { LC- COVID+ } \\
\quad(\mathrm{n}=333)\end{array}$ & $p$ value \\
\hline Male sex, \% & $40(59.7)$ & $197(59 \cdot 3)$ & $200(60.1)$ & 0.98 \\
\hline Age, yr & $59 \cdot 9 \pm 15 \cdot 7$ & $60.3 \pm 15 \cdot 3$ & $59.8 \pm 15 \cdot 5$ & 0.91 \\
\hline \multicolumn{5}{|l|}{ Region of diagnosis } \\
\hline Daegu \& Gyeongbuk & $43(64.2)$ & $212(63.9)$ & $215(64.6)$ & 0.98 \\
\hline \multicolumn{5}{|l|}{ Testing hospital } \\
\hline $3 \mathrm{rd}$ & $9(13.4)$ & $45(13 \cdot 6)$ & $43(12.9)$ & 0.97 \\
\hline \multicolumn{5}{|l|}{ Comorbidities } \\
\hline Decompensated liver cirrhosis ${ }^{\mathrm{a}, \mathrm{b}}$ & $19(28.4)$ & $154(46.4)$ & 0 & $<0.01$ \\
\hline Diabetes $^{\mathrm{b}}$ & $21(31.3)$ & $121(36.5)$ & $68(20.4)$ & $<0.01$ \\
\hline Hypertension $^{\mathrm{a}}$ & $27(40.3)$ & $185(55 \cdot 7)$ & $135(40.5)$ & $<0.01$ \\
\hline Dyslipidemia & $19(28.4)$ & $127(38.3)$ & $116(34.8)$ & 0.27 \\
\hline Cardiovascular disease $^{\mathrm{a}}$ & $9(13.4)$ & $82(24 \cdot 7)$ & $44(13.2)$ & $<0.01$ \\
\hline Cancer $^{\mathrm{a}, \mathrm{b}}$ & $12(17 \cdot 9)$ & $113(34 \cdot 0)$ & $20(6.0)$ & $<0.01$ \\
\hline $\mathrm{COPD}^{\mathrm{a}}$ & $9(13 \cdot 4)$ & $87(26.2)$ & $54(16.2)$ & $<0.01$ \\
\hline Asthma & $12(17 \cdot 9)$ & $77(23.2)$ & $52(15 \cdot 6)$ & 0.04 \\
\hline ESRD with dialysis ${ }^{\mathrm{a}}$ & o & $21(6.3)$ & 0 & $<0.01$ \\
\hline Immunocompromised status ${ }^{\mathrm{b}}$ & $9(13 \cdot 4)$ & $31(9 \cdot 3)$ & $13(3.9)$ & $<0.01$ \\
\hline $\mathrm{CCI}^{\mathrm{a}, \mathrm{b}}$ & $4.3 \pm 2.7$ & $6.3 \pm 3.8$ & $2.2 \pm 2.2$ & $<0.01$ \\
\hline
\end{tabular}

Values are presented as number (\%) or mean \pm standard deviation.

COVID-19, coronavirus disease 2019; LC, liver cirrhosis; COPD, chronic obstructive pulmonary disease; ESRD, end-stage renal disease; CCI, Charlson comorbidity index.

${ }^{\mathrm{a}} \mathrm{p}<0.05$ between LC+ COVID+ and LC+ COVID-.

${ }^{\mathrm{b}} \mathrm{p}<0.05$ between LC+ COVID+ and LC- COVID+.

perienced severe complications as previously defined (Table 2). The number of patients with severe complications were 18,54 , and $60(26.9 \%, 16.3 \%$, and $18.0 \%)$ in the LC+ COVID+, LC+ COVID-, and LC- COVID+ groups, respectively. No statistical difference was observed in the rate of development of severe complications among the three groups $(p=0.12)$. Of the 67 in the LC+ COVID+ group, $12(17.9 \%)$ needed oxygen therapy, four (6.0\%) required vasopressors, two (3.0\%) were admitted to ICU, and one received continuous renal replacement therapy. Death occurred in 6, 32, and 23 (9.0\%, 9.6\%, and 6.9\%) in the LC+ COVID+, LC+ COVID-, and LC- COVID+ groups, respectively, with no statistical difference among the three groups $(p=0.44)$. Besides, from the perspective of LC-related complications, there were no significant differences between the LC+COVID+ and LC+COVIDgroups $(p=0.22)$ (Table 2).

\section{Association between LC and complications of COVID-19}

Patients who were infected with COVID-19 and had LC (LC+ COVID+) were more likely to develop severe complications than those without LC (LC- COVID+). However, after adjusting for underlying medical comorbidities, there was no significant difference in the risk of developing severe complications between these two groups (adjusted odds ratio [AOR], 1.082; $p=0.87$ ) (Table 3). In addition, the proportion of patients who required oxygen therapy and who died did not significantly differ between the two groups regardless of the presence of LC (AOR for oxygen therapy and death, 1.095 and 6.426, respectively; $p>0.05$ for both).

Notably, of the patients with LC, COVID-19 infection (LC+ COVID+) was associated with poorer outcomes compared with LC+ COVID- group, even after adjusting 
Table 2. Rate of complications according to the presence of liver cirrhosis and COVID-19 infection $(n=732)$

\begin{tabular}{|c|c|c|c|c|}
\hline Variable & $\begin{array}{c}\text { LC+ COVID+ } \\
\quad(\mathrm{n}=67)\end{array}$ & $\begin{array}{c}\text { LC+ COVID- } \\
(\mathrm{n}=332)\end{array}$ & $\begin{array}{c}\text { LC- COVID+ } \\
(\mathrm{n}=333)\end{array}$ & $p$ value \\
\hline Severe complications $^{\mathrm{a}}$ & $18(26.9)$ & $54(16.3)$ & $60(18.0)$ & 0.12 \\
\hline Oxygen therapy $^{\mathrm{a}}$ & $12(17 \cdot 9)$ & $32(9.6)$ & $49(14.7)$ & 0.06 \\
\hline Vasopressors & $4(6.0)$ & $14(4.2)$ & $11(3 \cdot 3)$ & 0.56 \\
\hline Admission to intensive care unit & $2(3.0)$ & $9(2.7)$ & $8(2.4)$ & 0.95 \\
\hline Continuous renal replacement therapy & $1(1.5)$ & $1(0.3)$ & $3(0.9)$ & 0.45 \\
\hline Death & $6(9.0)$ & $32(9.6)$ & $23(6.9)$ & 0.44 \\
\hline LC-related complications & $3(4 \cdot 5)$ & $30(9.0)$ & - & 0.22 \\
\hline Variceal bleeding & $2(3.0)$ & $15(4 \cdot 5)$ & - & 0.57 \\
\hline Ascites & $2(3.0)$ & $23(6.9)$ & - & 0.22 \\
\hline Hepatorenal syndrome & 0 & $3(0.9)$ & - & 0.99 \\
\hline Spontaneous bacterial peritonitis & o & $1(0.3)$ & - & 0.99 \\
\hline Encephalopathy & $3(4 \cdot 5)$ & $17(5.1)$ & - & 0.99 \\
\hline
\end{tabular}

Values are presented as number (\%).

COVID-19, coronavirus disease 2019; LC, liver cirrhosis.

${ }^{\mathrm{a}} \mathrm{p}<0.05$ between LC+ COVID+ and LC+ COVID-.

Table 3. Association between liver cirrhosis and developing complications of COVID-19 infection

\begin{tabular}{|c|c|c|c|c|c|c|c|}
\hline Variable & $\begin{array}{l}\text { No. of } \\
\text { case }\end{array}$ & $\begin{array}{c}\text { Crude OR } \\
(95 \% \mathrm{CI})\end{array}$ & $p$ value & $\begin{array}{l}\text { Adjusted OR } \\
(95 \% \mathrm{CI})\end{array}$ & $p$ value & $\begin{array}{c}\text { Adjusted OR } \\
(95 \% \mathrm{CI})\end{array}$ & $p$ value \\
\hline \multicolumn{8}{|c|}{ Severe complications } \\
\hline LC+ COVID+ & 67 & Reference & & Reference & & Reference & \\
\hline LC+ COVID- & 332 & $0.468(0.238-0.919)$ & 0.03 & $0.408^{\mathrm{a}}(0.199-0.835)$ & 0.01 & $0.356^{\mathrm{b}}(0.170-0.745)$ & 0.01 \\
\hline LC-COVID+ & 333 & $0.538(0.270-1.071)$ & 0.08 & $0.811^{\mathrm{a}}(0.360-1.830)$ & 0.61 & $1.082^{\mathrm{c}}(0.416-2.817)$ & 0.87 \\
\hline \multicolumn{8}{|l|}{ Oxygen therapy } \\
\hline LC+ COVID+ & 67 & Reference & & Reference & & Reference & \\
\hline LC+ COVID- & 332 & $0.438(0.202-0.949)$ & 0.04 & $0.425^{\mathrm{a}}(0.187-0.964)$ & 0.04 & $0.35^{\mathrm{b}}(0.153-0.840)$ & 0.02 \\
\hline LC-COVID+ & 333 & $0.789(0.374-1.661)$ & 0.53 & $1.041^{\mathrm{a}}(0.436-2.484)$ & 0.93 & $1.095^{\mathrm{c}}(0.421-2.844)$ & 0.85 \\
\hline \multicolumn{8}{|l|}{ Death } \\
\hline LC+ COVID+ & 67 & Reference & & Reference & & Reference & \\
\hline LC+ COVID- & 332 & $1.078(0.421-2.762)$ & 0.88 & $0.817^{\mathrm{a}}(0.295-2.258)$ & 0.70 & $0.712^{\mathrm{b}}(0.252-2.010)$ & 0.52 \\
\hline LC- COVID+ & 333 & $0.748(0.266-2.101)$ & 0.58 & $1.787^{\mathrm{a}}(0.469-6.806)$ & 0.39 & $6.426^{c}(0.733-56.368)$ & 0.09 \\
\hline \multicolumn{8}{|c|}{ Liver cirrhosis-related complications } \\
\hline LC+ COVID+ & 67 & Reference & & Reference & & Reference & \\
\hline LC+ COVID- & 332 & $0.472(0.140-1.594)$ & 0.23 & $0.389(0.105-1.449)$ & 0.16 & $0.354^{\mathrm{b}}(0.091-1.379)$ & 0.13 \\
\hline
\end{tabular}

COVID-19, coronavirus disease 2019; OR, odds ratio; CI, confidence interval; LC, liver cirrhosis.

${ }^{a}$ Model 1: adjusted for hypertension, dyslipidemia, and the Charlson comorbidity index (CCI).

${ }^{\mathrm{b}}$ Model 2: adjusted for decompensated liver cirrhosis, hypertension, cardiovascular disease, cancer, chronic obstructive pulmonary disease, end-stage renal disease with dialysis, and the CCI.

${ }^{\mathrm{c}}$ Model 3: adjusted for decompensated liver cirrhosis, diabetes, cancer, immunocompromised status, and the CCI. 
for underlying comorbidities (Table 3). Moreover, cirrhotic patients infected with COVID-19 (LC+ COVID+) appeared to have a higher death rate than those patients with cirrhosis who were not infected with COVID-19 (LC+ COVID-) despite the lack of statistical significance. In addition, COVID-19 infection was not associated with the development of LC-related complications in the multivariate analysis (Table 3).

\section{Comparison of the clinical characteristics between those with and without severe complications}

Of the patients in the LC+ COVID+ group, those who developed severe complications were older and more likely to have hypertension, cancer, COPD, and a higher CCI than those who did not develop severe complica- tions from COVID-19 (Table 4). Of the patients in the LC- COVID+ group, severe complications were more likely to develop in older patients and those with diabetes, hypertension, dyslipidemia, COPD, and a higher CCI.

\section{DISCUSSION}

Our nationwide cohort study of the Republic of Korea suggests that the presence of LC was not independently associated with a higher risk of severe complications in patients with COVID-19 per se. On the contrary, in cirrhotic patients, the COVID-19 infection was more likely to cause severe complications when compared to the

Table 4. Baseline characteristics of patients with liver cirrhosis and COVID-19 infection according to the presence of complications $(n=400)$

\begin{tabular}{|c|c|c|c|c|c|c|}
\hline \multirow[b]{2}{*}{ Characteristic } & \multicolumn{3}{|c|}{ LC+ COVID+ } & \multicolumn{3}{|c|}{ LC-COVID+ } \\
\hline & $\begin{array}{l}\text { Complications+ } \\
(\mathrm{n}=18)\end{array}$ & $\begin{array}{l}\text { Complications- } \\
(\mathrm{n}=49)\end{array}$ & $p$ value & $\begin{array}{l}\text { Complications+ } \\
(\mathrm{n}=60)\end{array}$ & $\begin{array}{l}\text { Complications- } \\
(\mathrm{n}=273)\end{array}$ & $p$ value \\
\hline Male sex & $12(66.7)$ & $28(57 \cdot 1)$ & 0.48 & $33(55 \cdot 0)$ & $167(61.2)$ & 0.38 \\
\hline Age, yr & $68.9 \pm 13.0$ & $56.6 \pm 15.4$ & $<0.01$ & $71.8 \pm 13.0$ & $57.2 \pm 14.8$ & $<0.01$ \\
\hline \multicolumn{7}{|l|}{ Region of diagnosis } \\
\hline Daegu \& Gyeongbuk & $7(38.9)$ & $17(34.7)$ & 0.75 & $43(71.7)$ & $172(63.0)$ & 0.20 \\
\hline \multicolumn{7}{|l|}{ Testing hospital } \\
\hline $3 \mathrm{rd}, \%$ & $5(27.8)$ & $4(8.2)$ & 0.05 & $12(20.0)$ & $31(11.4)$ & 0.07 \\
\hline \multicolumn{7}{|l|}{ Comorbidities } \\
\hline $\begin{array}{l}\text { Decompensated liver } \\
\text { cirrhosis }\end{array}$ & $7(38.9)$ & $12(24 \cdot 5)$ & 0.25 & o & o & - \\
\hline Diabetes & $8(44 \cdot 4)$ & $13(26.5)$ & 0.16 & $21(35.0)$ & $47(17.2)$ & $<0.01$ \\
\hline Hypertension & $12(66.7)$ & $15(30.6)$ & $<0.01$ & $35(58.3)$ & $100(36.6)$ & $<0.01$ \\
\hline Dyslipidemia & $5(27.8)$ & $14(28.6)$ & 0.95 & $31(51.7)$ & $85(31.1)$ & $<0.01$ \\
\hline $\begin{array}{l}\text { Cardiovascular } \\
\text { disease }\end{array}$ & $3(16.7)$ & $6(12.2)$ & 0.69 & $12(20.0)$ & $32(11.7)$ & 0.09 \\
\hline Cancer & $8(44 \cdot 4)$ & $4(8.2)$ & $<0.01$ & $7(11.7)$ & $13(4.8)$ & 0.06 \\
\hline COPD & $7(38.9)$ & $2(4.1)$ & $<0.01$ & $16(26.7)$ & $38(13.9)$ & 0.02 \\
\hline Asthma & $4(22.2)$ & $8(16.3)$ & 0.72 & $12(20.0)$ & $40(14.7)$ & 0.30 \\
\hline ESRD with dialysis & 0 & $\mathrm{o}(0)$ & - & 0 & 0 & - \\
\hline $\begin{array}{l}\text { Immunocompro- } \\
\text { mised status }\end{array}$ & $1(5.6)$ & $8(16.3)$ & 0.43 & $2(3 \cdot 3)$ & $11(4.0)$ & 1.00 \\
\hline CCI & $5.6 \pm 3.1$ & $3.9 \pm 2.4$ & 0.02 & $3.5 \pm 2.3$ & $1.9 \pm 2.0$ & $<0.01$ \\
\hline
\end{tabular}

Values are presented as number (\%) or mean \pm standard deviation.

COVID-19, coronavirus disease 2019; LC, liver cirrhosis; COPD, chronic obstructive pulmonary disease; ESRD, end-stage renal disease; CCI, Charlson comorbidity index. 
cirrhotic patients without COVID-19 infection included in the study. Development of severe complications from COVID-19 in patients with cirrhosis was significantly associated with older age, hypertension, cancer, COPD, and a higher CCI as reported in previous studies.

It remains unanswered whether pre-existing liver diseases, including LC, are prognostic factors in patients with COVID-19. COVID-19-related liver injury has received much attention recently; it is defined as any liver damage occurring during the disease progression and treatment of COVID-19. Elevated liver enzymes are frequently observed in patients with COVID-19, particularly in severe cases. However, the exact pathogenesis of COVID-19-related liver injury has not yet been elucidated. In addition, the elevated liver enzymes caused by COVID-19 infection might have many causes, such as direct liver injury from COVID-19, sepsis-associated cholestasis, and drug-induced liver injury during the treatment of COVID-19 [21,22]. The drug treatment for COVID-19 includes lopinavir/ritonavir, remdesivir, chloroquine, and tocilizumab which are associated with various degrees of liver injury [23-25]. Most recent studies argue that COVID-19-related liver injuries are usually transitory and of a mild degree, with little clinical significance [22]. Indeed, liver failure leading to death in patients with COVID-19 has rarely been reported and whether the liver failure was directly caused by COVID-19 remained ambiguous [26]. Notably, our results did not show a significant association between the development of severe complications from COVID-19 and the presence of LC.

Contrary to our findings, LC was independently associated with an increased risk of death in a recent large observational study, which included 54 (1.3\%) patients with COVID-19 and LC out of 3,998 hospitalized patients [27]. A study from China reported that disease progression was significantly higher in COVID-19 patients with chronic liver disease, including LC, when compared to those without chronic liver disease [28]. However, out of a total of 140 patients, this report only included three patients with cirrhosis. Another prospective study from North America suggested that LC+ COVID+ patients had a higher mortality than LC- COVID+ patients [11]. However, most of these studies were derived from hospitalized patients $[10-13,21]$. The severity of liver injury in or impact of cirrhosis on COVID-19 infection in asymp- tomatic or mildly symptomatic cirrhotic patients is unknown. In this regard, compared with the above studies, we not only included patients who were hospitalized for COVID-19 but also mild cases that were not admitted to hospital. Therefore, the significant association between the severe complications of COVID-19 and presence of LC might be less evident when compared with previous reports. Another plausible explanation could be the difference in the etiologies of LC between our study and previous studies. Non-alcoholic fatty liver disease and alcoholic liver disease are the most common etiologies of LC in Europe and North America. Obesity, diabetes, dyslipidemia, and hypertension, which tend to be accompanied by non-alcoholic fatty liver disease were proven to be associated with a higher risk of severe complications in patients with COVID-19. However, chronic hepatitis B is attributable as the etiology for more than 70\% of LC cases in Korea [29]. The inconsistency of our results when compared with other reports may partly be attributed to this difference in LC etiologies. In addition, it is important to note that so far studies evaluating the impact of cirrhosis on the prognosis of COVID-19 infection have many limitations because of the small number of cases and various study designs. When taken together, it is currently difficult to conclude that cirrhotic patients with COVID-19 have an increased risk of severe complications or mortality comparing with the patients with COVID-19 only, despite the general expectation of a poor outcome in patients with LC and COVID-19 infection [30].

Our study is consistent with previous reports regarding the prognostic factors for severe complications of COVID-19 in the patients with cirrhosis and COVID-19, such as older age, hypertension, cancer, COPD, and a higher CCI [31]. This implies that underlying medical comorbidities other than cirrhosis may aggravate the course of COVID-19 infection. These comorbidities are known to leave patients vulnerable to developing the severe complications of COVID-19 [2,5,32-34].

Interestingly, cirrhotic patients with COVID-19 (LC+ COVID+) appeared to have about a three-fold risk of severe complications, when compared to those with cirrhosis only (LC+ COVID-). Although this result did not address a direct comparison between the LC+ COVID+ and LC+ COVID- groups, this indicates that patients with cirrhosis were more vulnerable to worse outcomes 
when they were infected with COVID-19 during this pandemic. A multicenter prospective study from North America showed a similar trend but the statistical significance was not attained [11].

There are several limitations to our study. We used data from the National Health Insurance claims database and baseline clinical characteristics were derived from ICD-10 codes. Coding accuracy of disease conditions could be a limiting factor. However, the definitions we used in the study were rigorously validated and are widely used in this type of nationwide cohort study [35]. In addition, although we included all cirrhotic patients with COVID-19+ among Koreans who were tested for COVID-19, we were able to include 67 cirrhotic patients with COVID-19 infection. Because the absolute number of included cases seemed relatively small, our findings might not be generalizable. However, considering the low prevalence of cirrhosis among the general population, our study included one of the largest numbers of cirrhotic patients with COVID-19 infection. Another limitation of the present study was that there were significant differences in comorbidities among the three groups. However, we applied a propensity score matching method and adjusted various comorbidities to minimize the confounding caused by these differences.

Our data were not able to include laboratory parameters such as the Child-Pugh score and model for endstage liver disease to accurately assess liver function in the patients with LC. Given that other underlying comorbidities may affect the course of COVID-19 infection more than cirrhosis, we adjusted for these comorbidities, including decompensated cirrhosis, in our analysis. From our study, the susceptibility of cirrhotic patients to COVID-19 infection remains elusive. Although no difference was found in the susceptibility of patients with cirrhosis to COVID-19 infection (data not shown), it should be considered that many factors contribute to the susceptibility of certain diseases to COVID-19 and that this is very difficult to evaluate in an infection that is as highly contagious as this.

Our study included several statistical measures to account for the possible biases that may be associated with such unequal distributions of the COVID-19 outbreak. Until May 15, 2020, 74.8\% of the patients in South Korea were from the Daegu and Gyeongbuk regions. To reduce the effects of possible biases, we have added the details of distinct epidemiology and testing hospital as additional variables.

In conclusion, our nationwide cohort study of the Republic of Korea suggests that LC per se was not independently associated with the development of severe complications, including mortality, in patients with COVID-19. Older age, hypertension, COPD, and a higher CCI score were associated with poorer outcomes in patients with COVID-19, as previously reported. However, the impact of LC on the outcome of COVID-19 infection needs to be examined in future prospective studies with large numbers of patients.

\section{KEY MESSAGE}

1. Liver cirrhosis was not independently associated with the development of severe complications, including mortality, in coronavirus disease 2019 (COVID-19) infection.

2. In patients with cirrhosis and COVID-19, older age, hypertension, cancer, chronic obstructive pulmonary disease, and a higher Charlson comorbidity index were associated with a higher risk of severe complications.

\section{Conflict of interest}

No potential conflict of interest relevant to this article was reported.

\section{Acknowledgments}

The authors appreciate the Ministry of Health and Welfare and the Health Insurance Review and Assessment Service of Korea for providing invaluable National Health Insurance claims data in a prompt manner.

\section{REFERENCES}

1. Del Rio C, Malani PN. 2019 Novel coronavirus: important information for clinicians. JAMA 2020;323:1039-1040.

2. Guan WJ, Ni ZY, Hu Y, et al. Clinical characteristics of coronavirus disease 2019 in China. N Engl J Med 2020;382:1708-1720.

3. Bhatraju PK, Ghassemieh BJ, Nichols M, et al. Covid-19 in critically ill patients in the Seattle region: case series. N 
Engl J Med 2020;382:2012-2022.

4. Centers for Disease Control and Prevention. People of any age with underlying medical conditions [Internet]. Atlanta (GA): CDC, 2020 [cited 2021 Jun 8]. Available from: https://stacks.cdc.gov/view/cdc/90727.

5. Grasselli G, Zangrillo A, Zanella A, et al. Baseline characteristics and outcomes of 1591 patients infected with SARS-CoV-2 admitted to ICUs of the Lombardy region, Italy. JAMA 2020;323:1574-1581.

6. Dai M, Liu D, Liu M, et al. Patients with cancer appear more vulnerable to SARS-CoV-2: a multicenter study during the COVID-19 outbreak. Cancer Discov 2020;10:783-791.

7. Kumar-M P, Mishra S, Jha DK, et al. Coronavirus disease (COVID-19) and the liver: a comprehensive systematic review and meta-analysis. Hepatol Int 2020;14:711-722.

8. Richardson S, Hirsch JS, Narasimhan M, et al. Presenting characteristics, comorbidities, and outcomes among 5700 patients hospitalized with COVID-19 in the New York city area. JAMA 2020;323:2052-2059.

9. Albillos A, Lario M, Alvarez-Mon M. Cirrhosis-associated immune dysfunction: distinctive features and clinical relevance. J Hepatol 2014;61:1385-1396.

10. Moon AM, Webb GJ, Aloman C, et al. High mortality rates for SARS-CoV-2 infection in patients with pre-existing chronic liver disease and cirrhosis: preliminary results from an international registry. J Hepatol 2020;73:705708.

11. Bajaj JS, Garcia-Tsao G, Biggins SW, et al. Comparison of mortality risk in patients with cirrhosis and COVID-19 compared with patients with cirrhosis alone and COVID-19 alone: multicentre matched cohort. Gut 2020:gutjnl-2020-322118.

12. Iavarone M, D'Ambrosio R, Soria A, et al. High rates of 30day mortality in patients with cirrhosis and COVID-19. J Hepatol 2020;73:1063-1071.

13. Singh S, Khan A. Clinical characteristics and outcomes of coronavirus disease 2019 among patients with preexisting liver disease in the United States: a multicenter research network study. Gastroenterology 2020;159:768-771.

14. Gao F, Huang ZM. The impact of COVID-19 on the clinical outcome of patients with cirrhosis deserves more attention and research. J Hepatol 2020;73:1568-1569.

15. Hong KH, Lee SW, Kim TS, et al. Guidelines for laboratory diagnosis of coronavirus disease 2019 (COVID-19) in Korea. Ann Lab Med 2020;40:351-360.
16. Chung W, Jo C, Chung WJ, Kim DJ. Liver cirrhosis and cancer: comparison of mortality. Hepatol Int 2018;12:269276.

17. De Groot V, Beckerman H, Lankhorst GJ, Bouter LM. How to measure comorbidity: a critical review of available methods. J Clin Epidemiol 2003;56:221-229.

18. Jung SY, Choi JC, You SH, Kim WY. Association of renin-angiotensin-aldosterone system inhibitors with coronavirus disease 2019 (COVID-19). Related outcomes in Korea: a nationwide population-based cohort study. Clin Infect Dis 2020;71:2121-2128.

19. Son M, Seo J, Yang S. Association between renin-angiotensin-aldosterone system inhibitors and COVID-19 infection in South Korea. Hypertension 2020;76:742-749.

20. Oh H, Jun DW, Lee IH, et al. Increasing comorbidities in a South Korea insured population-based cohort of patients with chronic hepatitis B. Aliment Pharmacol Ther 2020;52:371-381.

21. Wong GL, Wong VW, Thompson A, et al. Management of patients with liver derangement during the COVID-19 pandemic: an Asia-Pacific position statement. Lancet Gastroenterol Hepatol 2020;5:776-787.

22. Garrido I, Liberal R, Macedo G. Review article. COVID-19 and liver disease: what we know on 1st May 2020. Aliment Pharmacol Ther 2020;52:267-275.

23. Bijlsma JW, Welsing PM, Woodworth TG, et al. Early rheumatoid arthritis treated with tocilizumab, methotrexate, or their combination (U-Act-Early): a multicentre, randomised, double-blind, double-dummy, strategy trial. Lancet 2016;388:343-355.

24. Palacios R, Vergara S, Rivero A, et al. Low incidence of severe liver events in HIV patients with and without hepatitis $\mathrm{C}$ or B coinfection receiving lopinavir/ritonavir. HIV Clin Trials 2006;7:319-323.

25. Grein J, Ohmagari N, Shin D, et al. Compassionate use of remdesivir for patients with severe COVID-19. N Engl J Med 2020;382:2327-2336.

26. Weber S, Mayerle J, Irlbeck M, Gerbes AL. Severe liver failure during SARS-CoV-2 infection. Gut 2020;69:13651367.

27. Berenguer J, Ryan P, Rodriguez-Bano J, et al. Characteristics and predictors of death among 4035 consecutively hospitalized patients with COVID-19 in Spain. Clin Microbiol Infect 2020;26:1525-1536.

28. Ji D, Zhang D, Yang T, et al. Effect of COVID-19 on patients with compensated chronic liver diseases. Hepatol 
Int 2020;14:701-710.

29. Choi J, Han S, Kim N, Lim YS. Increasing burden of liver cancer despite extensive use of antiviral agents in a hepatitis B virus-endemic population. Hepatology 2017;66:1454-1463.

30. Boettler T, Marjot T, Newsome PN, et al. Impact of COVID-19 on the care of patients with liver disease: EASL-ESCMID position paper after 6 months of the pandemic. JHEP Rep 2020;2:100169.

31. Wu Z, McGoogan JM. Characteristics of and important lessons from the coronavirus disease 2019 (COVID-19) outbreak in China: summary of a report of 72314 cases from the Chinese Center for Disease Control and Prevention. JAMA 2020;323:1239-1242.

32. Zhou YJ, Zheng KI, Wang XB, et al. Younger patients with
MAFLD are at increased risk of severe COVID-19 illness: a multicenter preliminary analysis. J Hepatol 2020;73:719721.

33. Docherty AB, Harrison EM, Green CA, et al. Features of 20133 UK patients in hospital with covid-19 using the ISARIC WHO clinical characterisation protocol: prospective observational cohort study. BMJ 2020;369:m1985.

34. Cai Q, Chen F, Wang T, et al. Obesity and COVID-19 severity in a designated hospital in Shenzhen, China. Diabetes Care 2020;43:1392-1398.

35. Lee SW, Ha EK, Yeniova AO, et al. Severe clinical outcomes of COVID-19 associated with proton pump inhibitors: a nationwide cohort study with propensity score matching. Gut 2020:gutjnl-2020-322248. 


\section{KJIM}

\section{Supplementary Table 1. Definition of the comorbidities}

\begin{tabular}{|c|c|c|}
\hline Diagnosis & ICD-10 codes & Claim codes \\
\hline Decompensated liver cirrhosis & $\mathrm{K}_{72.0}, \mathrm{~K}_{72.1}, \mathrm{~K}_{72.9}, \mathrm{R} 18, \mathrm{I}_{5} .0, \mathrm{I}_{9} 8.3$ & Admission or outpatient department $\geq 1$ \\
\hline Diabetes & E10-E14 & Prescription of anti-diabetic drugs $\geq 1$ \\
\hline Hypertension & I10-I11 & Prescription of anti-hypertensive drugs $\geq 1$ \\
\hline Dyslipidemia & E78 & Prescription of lipid-lowering drugs $\geq 1$ \\
\hline Cardiovascular disease & $\begin{array}{l}\text { I21-I24 for myocardial infarction, } \\
\text { I60-I69 for stroke }\end{array}$ & Admission or outpatient department $\geq 1$ \\
\hline Cancer & Coo-C97 & Admission or outpatient department $\geq 1$ \\
\hline COPD & J41-J44 & Admission or outpatient department $\geq 1$ \\
\hline Asthma & $\mathrm{J} 45-\mathrm{J} 46$ & Admission or outpatient department $\geq 1$ \\
\hline ESRD with dialysis & $\mathrm{N} 18-\mathrm{N}_{19}, \mathrm{Z}_{49}, \mathrm{Z}_{99.2}$ & $\begin{array}{l}\text { O701-O702 for hemodialysis } \geq 1 \text { or } \mathrm{O}_{707} \text { for perito- } \\
\text { neal dialysis } \geq 1\end{array}$ \\
\hline Immunocompromised status & $\begin{array}{l}\text { Mo5-Mo9, } \mathrm{M}_{30-\mathrm{M}_{3} 6} \text { for autoimmune } \\
\text { disease, B20-B24, F24, O987, Z21 for } \\
\text { HIV/AIDS }\end{array}$ & Admission or outpatient department $\geq 1$ \\
\hline
\end{tabular}

ICD-10, International Classification of Diseases, 1oth revision; COPD, chronic obstructive pulmonary disease; ESRD, endstage renal disease; HIV, human immunodeficiency virus; AIDS, acquired immune deficiency syndrome. 
Jeon D, et al. Liver cirrhosis with COVID-19

Supplementary Table 2. ICD-10 codes for complications

\begin{tabular}{|c|c|}
\hline & ICD-10 codes or HIRA general name code \\
\hline \multicolumn{2}{|l|}{ Severe complications } \\
\hline Oxygen therapy & Moo4o, Moo46, M5850, M5857, M5858, M5859, M586o \\
\hline Vasopressors & $\begin{array}{l}\text { Norepinephrine: } 2031 \\
\text { Epinephrine: } 3138,1526,6694 \\
\text { Vasopressin: } 2473 \\
\text { Dopamine: } 1487,3894,3895,3897,4295 \\
\text { Dobutamine: } 1482,3890,3996\end{array}$ \\
\hline Admission for intensive care unit & Claim codes including ‘AJ' \\
\hline Continuous renal replacement therapy & $\mathrm{O}_{7031}, \mathrm{O}_{7032}, \mathrm{O}_{7033}, \mathrm{O}_{7034}, \mathrm{O}_{7035}, \mathrm{O}_{7051}, \mathrm{O}_{7052}, \mathrm{O}_{7053}, \mathrm{O}_{7054}, \mathrm{O}_{7055}$ \\
\hline \multicolumn{2}{|l|}{ Liver cirrhosis related complications } \\
\hline Varix & $\begin{array}{l}\text { At least } 1 \text { or more medical record by year via I850, I859, } \\
\text { At least } 1 \text { or more medical record by year via I850, I859 \& K74 } \\
\text { Prescribed with beta-blocker }(2199,1250,6622) \text { along with K74 }\end{array}$ \\
\hline Ascites & $\begin{array}{l}\text { At least } 1 \text { or more medical record by year via } \mathrm{R} 18 \text { \& } \mathrm{K}_{74} \\
\text { Prescribed with diuretic }(1638,2420,2627,2311) \text { along with } \mathrm{K}_{74} \\
\text { Prescribed with albumin }(2271,3697) \text { along with } \mathrm{K}_{74} \text { and abdominal paracentesis } \\
(\mathrm{C} 8050)\end{array}$ \\
\hline Hepatorenal syndrome & $\begin{array}{l}\text { At least } 1 \text { or more medical record by year via } \mathrm{K}_{7} 67 \\
\text { Prescribed with terlipressin }(2360) \text { \& albumin }(2271,3697) \text { for more than } 4 \text { days }\end{array}$ \\
\hline Spontaneous bacterial peritonitis & $\begin{array}{l}\text { At least } 1 \text { or more medical record by year via } \mathrm{K} 658, \mathrm{~K} 659, \mathrm{~K} 74 \text {, and abdominal } \\
\text { paracentesis }(\mathrm{C} 8050) \text { simultaneously }\end{array}$ \\
\hline Encephalopathy & $\begin{array}{l}\text { Prescribed with duphalac (1808) along with } \mathrm{K}_{74} \\
\text { Prescribed with duphalac (1808) along with enema procedure }\end{array}$ \\
\hline
\end{tabular}

ICD-10, International Classification of Diseases, 1oth revision; HIRA, Health Insurance Review and Assessment Service. 
Supplementary Table 3. Baseline characteristics of patients with liver cirrhosis grouped according to the COVID-19 infection before case-control matching $(n=13,681)$

\begin{tabular}{|c|c|c|c|c|}
\hline Characteristic & $\begin{array}{c}\mathrm{LC}+\text { COVID+ } \\
\quad(\mathrm{n}=67)\end{array}$ & $\begin{array}{l}\text { LC+ COVID- } \\
\quad(\mathrm{n}=6,395)\end{array}$ & $\begin{array}{c}\text { LC- COVID+ } \\
\quad(\mathrm{n}=7,219)\end{array}$ & $p$ value \\
\hline Male sex ${ }^{\mathrm{a}}$ & $40(59.7)$ & $4,076(63.7)$ & $2,896(40.1)$ & $<0.01$ \\
\hline Age, $\mathrm{yr}^{\mathrm{a}, \mathrm{b}}$ & $59.9 \pm 15.7$ & $62.3 \pm 14.3$ & $47.2 \pm 18.9$ & $<0.01$ \\
\hline \multicolumn{5}{|l|}{ Region of diagnosis } \\
\hline Daegu \& Gyeongbuk ${ }^{\mathrm{a}}$ & $43(64.2)$ & $770(12.0)$ & $3,865(53.5)$ & $<0.01$ \\
\hline \multicolumn{5}{|l|}{ Tested hospital } \\
\hline $3 \mathrm{rd}^{\mathrm{a}}$ & $9(13.4)$ & $3,300(51.6)$ & $1,389(19.2)$ & $<0.01$ \\
\hline \multicolumn{5}{|l|}{ Comorbidities } \\
\hline Decompensated liver cirrhosis ${ }^{\mathrm{a}, \mathrm{b}}$ & $19(28.4)$ & $3,199(50.0)$ & 0 & $<0.01$ \\
\hline Diabetes $^{\mathrm{a}}$ & $21(31.3)$ & $2,488(38.9)$ & $802(11.1)$ & $<0.01$ \\
\hline Hypertension $^{\mathrm{a}, \mathrm{b}}$ & $27(40.3)$ & $3,645(57.0)$ & $1,714(23.7)$ & $<0.01$ \\
\hline Dyslipidemia & $19(28.4)$ & $2,329(36.4)$ & $1,584(21.9)$ & $<0.01$ \\
\hline Cardiovascular disease & $9(13.4)$ & $1,393(21.8)$ & $540(7 \cdot 5)$ & $<0.01$ \\
\hline Cancer $^{\mathrm{a}, \mathrm{b}}$ & $12(17.9)$ & $3,022(47 \cdot 3)$ & $330(4.6)$ & $<0.01$ \\
\hline $\mathrm{COPD}^{\mathrm{a}}$ & $9(13.4)$ & $1,763(27.6)$ & $726(10.1)$ & $<0.01$ \\
\hline Asthma & $12(17.9)$ & $1,472(23.0)$ & $915(12.7)$ & $<0.01$ \\
\hline ESRD with dialysis ${ }^{\mathrm{a}}$ & 0 & $387(6.1)$ & $20(0.3)$ & $<0.01$ \\
\hline Immunocompromised status ${ }^{\mathrm{a}}$ & $9(13.4)$ & $480(7.5)$ & $265(3.7)$ & $<0.01$ \\
\hline $\mathrm{CCI}^{\mathrm{a}, \mathrm{b}}$ & $4.3 \pm 2.7$ & $6.8 \pm 3.8$ & $1.4 \pm 1.9$ & $<0.01$ \\
\hline Severe complications ${ }^{\mathrm{a}, \mathrm{b}}$ & $18(26.9)$ & $1,068(16.7)$ & $686(9.5)$ & $<0.01$ \\
\hline Oxygen therapy ${ }^{\mathrm{a}, \mathrm{b}}$ & $12(17.9)$ & $631(9.9)$ & $574(7.8)$ & $<0.01$ \\
\hline Vasopressors $^{\mathrm{a}}$ & $4(6.0)$ & $267(4.2)$ & $97(1.3)$ & $<0.01$ \\
\hline Admission for intensive care unit & $2(3.0)$ & $252(3.9)$ & $110(1.5)$ & $<0.01$ \\
\hline Continuous renal replacement therapy & $1(1.5)$ & $44(0.7)$ & $21(0.3)$ & $<0.01$ \\
\hline Death $^{\mathrm{a}}$ & $6(9.0)$ & $501(7.8)$ & $225(3.1)$ & $<0.01$ \\
\hline Liver cirrhosis related complications & $3(4 \cdot 5)$ & $524(8.2)$ & - & 0.37 \\
\hline Varix & $2(3.0)$ & $195(3.1)$ & - & 1.00 \\
\hline Ascites & $2(3.0)$ & $350(5.5)$ & - & 0.59 \\
\hline Hepatorenal syndrome & 0 & $64(1.0)$ & - & 1.00 \\
\hline Spontaneous bacterial peritonitis & o & $11(0.2)$ & - & 1.00 \\
\hline Encephalopathy & $3(4 \cdot 5)$ & $233(3.6)$ & - & 0.74 \\
\hline
\end{tabular}

Values are presented as number (\%) or mean \pm standard deviation.

COVID-19, coronavirus disease 2019; LC, liver cirrhosis; COPD, chronic obstructive pulmonary disease; ESRD, end-stage renal disease; CCI, Charlson comorbidity index.

${ }^{\mathrm{a}} \mathrm{p}<0.05$ between LC+ COVID+ and LC- COVID+.

${ }^{\mathrm{b}} \mathrm{p}<0.05$ between LC+ COVID+ and LC+ COVID-. 